\title{
Sensibilidade da rosa 'Osiana' ao etileno
}

\author{
Delaine Cristina Cordeiro; Fernando Luiz Finger ( $\left.{ }^{*}\right)$; Joice Simone dos Santos; \\ Juliane Karsten; José Geraldo Barbosa
}

Universidade Federal de Viçosa, 36570-000 Viçosa (MG).

(*) Autor correspondente: ffinger@ufv.br

Recebido: 19/jul./2010; Aceito: 9/dez./2010

\begin{abstract}
Resumo
Os objetivos deste trabalho foram determinar a sensibilidade e as respostas da rosa cultivar Osiana (Rosa $\times$ hybrida) à presença de etileno ao longo da vida pós-colheita. Para determinar a sensibilidade da flor ao etileno, hastes foram cortadas e colocadas em câmaras herméticas e em seguida tratadas por 24 horas com diferentes concentrações de etileno variando de 0,0; 0,1; 1,0; 10; 100 e $1000 \mu \mathrm{L} \mathrm{L}^{-1}$ do ar no interior da câmara. A rosa teve a vida pós-colheita reduzida pelo etileno, quando

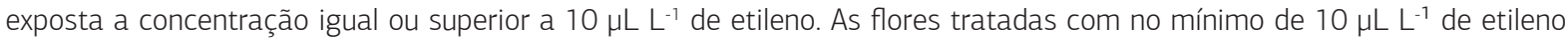
desenvolveram necrose, murcha e abscisão prematura das pétalas ainda túrgidas. As concentrações de 0,1 e $1,0 \mu \mathrm{L} \mathrm{L}^{-1}$ de etileno estimularam a abertura do botão floral durante o período de 24 horas de exposição ao etileno, sem no entanto, reduzir a vida pós-colheita. A rosa 'Osiana' pode ser classificada como uma cultivar sensível ao etileno e a concentração influência os processos estimulados.
\end{abstract}

Palavras-chave: pós-colheita, flores de corte, vida de vaso.

\section{Sensitivity of 'Osiana' rose to ethylene}

\section{Abstract}

The aim of this experiment was to determine the sensitivity and responses of the 'Osiana' (Rosa $\times$ hybrida ) rose to the presence of ethylene through postharvest life. The flower stems were placed in closed chambers and immediately treated with 0.0, 0.1, 1.0, 10, 100 and $1000 \mu \mathrm{LL}^{-1}$ ethylene for $24 \mathrm{~h}$. The postharvest life of the flower was reduced when exposed to 10 $\mu \mathrm{L} \mathrm{L}^{-1}$ ethylene or higher, with flowers developing necrosis, wilting and the petals prematurely abscising. Ethylene concentrations of 0.1 and $1.0 \mu \mathrm{L} \mathrm{L}^{-1}$ hastened the opening of flower buds within the $24 \mathrm{~h}$ of ethylene treatment, with no subsequent reduction of postharvest life. The flowers of rose 'Osiana' can be classified as sensitive to ethylene with the concentration influencing the stimulated processes.

Key words: postharvest, cut flower, vase life.

\section{INTRODUÇÃO}

No mercado brasileiro, as rosas destacam-se como uma das mais populares flor de corte, representando a maior área de produçáo de flores cortadas no Estado de Minas Gerais (Landgraf e Paiva, 2009). Conhecida popularmente como Rosa Chá, a rosa 'Osiana' é uma cultivar pertencente ao grupo híbrido Rosa-chá. Esta cultivar possui hastes longas e as flores são muito perfumadas, porém, a fama deste grupo deve-se a sua grande variedade de cores.

O conhecimento do comportamento fisiológico e dos fatores que afetam a longevidade pós-colheita das flores de corte é importante para permitir o transporte e armazenamento. Dentre os fatores determinantes da longevidade das flores de corte, estão a cultivar, sensibilidade ao etileno, relações hídricas, respiração e injúria por frio (Finger e Barbosa, 2006). O etileno é um regulador de crescimento produzido por quase todos os tecidos das plantas superiores e a taxa de produçáo e modo de ação dependem do tipo e estágio de desenvolvimento do tecido (SEREK et al., 2006). Como o etileno é um fito-hormônio responsável pelo envelhecimento e pela senescência das plantas, esse pode provocar vários efeitos indesejáveis, como enrolamento e murchamento das pétalas, abscisão de flores e folhas, elevação da respiração, degradação de clorofila e redução da matéria fresca provocada pela perda de água (LUTTs et al., 1996; Matile et al., 1997; Van Doorn e Woltering, 2008). Porém, a aplicação de inibidores da síntese, aminoetixivinilglicina (AVG) e da ação do etileno, o 1-metilciclopropeno (1-MCP) e tiosulfato de prata (STS) tem efeitos positivos em inibir os efeitos deletérios da ação do etileno sobre flores sensíveis ao fito-hormônio (Arora, 2008).

A senescência e a abscisão das flores são processos que envolvem mudanças na sensibilidade ao etileno. Em flores de cravo, lisianto, petúnia e orquídeas, a senescên- 
cia é determinada pela ação e taxa de produção de etileno (Serek et al., 2006). Porém, em rosas, a ação e a produção de etileno podem variar em função da cultivar, que é atribuída às diferenças na produção endógena ou sensibilidade ao fito-hormônio (Muller et al., 2000). Segundo MACNish et al. (2010), há grande variação na extensão da vida pós-colheita de 38 cultivares de rosas Hybrid Tea, e essa esteve associada ao grau de sensibilidade ao etileno. Os mesmos autores verificaram que em 27 cultivares houve murchamento e abscisão acelerada das pétalas em presença de etileno. Em minirrosas 'Victory Parade', a pulverização com ethephon reduziu a longevidade das flores e o uso de STS foi eficaz em prolongar a vida pós-colheita (Serek, 1993). Para a rosa 'Osiana', no entanto, não há trabalhos prévios de avaliação da longevidade e ação do etileno na pós-colheita das flores cortadas.

Woltering e VAN Doorn (1988) classificaram as cultivares comerciais de rosas em diferentes níveis de sensibilidade ao etileno, variando de altamente sensível a pouco sensível. Em consequência, as rosas têm respostas diferenciadas ao tratamento com etileno, variando da inibição da abertura floral, aceleração da abertura floral, abertura anormal, abscissão de folhas e pétalas ou sem nenhum efeito (Reid et al., 1989).

Devido a diferentes níveis de sensibilidade de rosas à ação do etileno, o objetivo deste trabalho foi determinar o grau de sensibilidade da rosa 'Osiana' ao etileno e seus efeitos sobre a evoluçáo da senescência e vida de vaso das flores.

\section{MATERIAL E MÉTODOS}

As flores da rosa híbrida 'Osiana' foram obtidas em campo de produção comercial no município de Barbacena (MG). O corte foi realizado no estádio ideal para a colheita como sugerido por Nowak e Rudnicki (1990), quando os botôes da rosa estavam com todas as sépalas abertas e o botão ainda fechado. Logo após a colheita, as rosas foram transportadas sem aporte de solução ou água até Viçosa (MG), onde as hastes foram selecionadas, uniformizadas e padronizadas para o comprimento de $50 \mathrm{~cm}$.

Para realização dos experimentos, câmaras herméticas foram construídas em compartimentos plásticos com volume de $103 \mathrm{~L}$, onde as hastes foram tratadas com etileno.

As flores foram acondicionadas em vaso com água dentro das câmaras herméticas, onde foram tratadas com concentraçôes de 0,$1 ; 1,0 ; 10 ; 100$ e $1000 \mu \mathrm{L} \mathrm{L}^{-1}$ de etileno por 24 horas sob condiçóes controladas de luz com $10 \mu \mathrm{mol} \mathrm{m}{ }^{-2} \mathrm{~s}^{-1} \mathrm{e}$ temperatura de $22^{\circ} \mathrm{C}$. No experimento, foram utilizados dois controles, um controle onde os vasos foram colocados na bancada do laboratório e outro controle na câmara hermética na ausência de etileno exógeno, para verificar se o fito-hormônio produzido pelas rosas e acumulado na câmara teria influencia sobre a fisiologia da flor. No decorrer das 24 horas de tratamento, concentração de etileno, no interior das câmaras herméticas, foi determinada em amostras da atmosfera interna, injetadas em cromatógrafo a gás modelo GC-14B Shimadzu GC$14 B$, equipado com coluna empacotada Porapak-Q e nitrogênio como gás de arraste (Finger et al., 2006). No interior das câmaras foram colocadas pastilhas de $\mathrm{NaOH}$ para evitar acúmulo de $\mathrm{CO}_{2}$ e interferir na síntese e ação do etileno. Decorrido o tempo de exposição ao etileno, as hastes florais foram retiradas das câmaras herméticas e mantidas em vaso contendo água destilada e sob as mesmas condiçôes de luz e temperatura.

Para analisar os efeitos dos tratamentos sobre a longevidade pós-colheita das rosas, diariamente foi avaliada a evolução da abertura floral do estádio de botão até os estádios de semiaberta e completamente aberta (Tabela 1 e Figura 1). A senescência da flor foi determinada pela presença de pétalas necrosadas, murcha e/ou abscisão ao longo do período pós-colheita (Tabela 1 e Figura 1). O fim da pós-colheita foi estabelecido quando as flores atingiram o mínimo do estádio - 2 da escala da senescência, ou seja, presença de varias pétalas externas com secamento e escurecimento (Figura 1).

O grau de sensibilidade da rosa 'Osiana' ao etileno foi interpretado em relação ao surgimento de sintomas de senescência estabelecido na tabela 1 e figura 1 e pelo fim da vida pós-colheita das flores dos tratamentos em relação ao controle sem o tratamento com etileno.

O experimento foi montado em delineamento inteiramente casualizado, com quatro repetições por tratamento, com três hastes florais por repetição. Os dados foram submetidos à análise de variância ANOVA e as médias dos tratamentos comparadas pelo teste de Dunnett ou Tukey a $5 \%$ de probabilidade de erro.

\section{RESULTADOS E DISCUSSÃO}

A longevidade da rosa 'Osiana' não foi afetada quando tratada por 24 horas com 0,1 ou $1,0 \mu \mathrm{L} \mathrm{L}^{-1}$ de etileno, com a vida pós-colheita não diferindo do controle em ambiente fechado ou aberto (Figura 2). Porém, na concentraçâo de $10 \mu \mathrm{L} \mathrm{L}^{-1}$ de etileno ou superior houve redução significativa da vida pós-colheita de 5,4 dias para aproximadamente 1,2 dias, com presença de queda prematura das pétalas sem sintomas aparentes de murcha (Figura 2). No tratamento onde as flores permaneceram por 24 horas nos frascos herméticos, ou controle fechado, o acúmulo de etileno foi inferior ao nível de detecção do cromatógrafo a gás $\left(0,05 \mu \mathrm{L} \mathrm{L}^{-1}\right)$, parecendo não haver influência significativa sobre a pós-colheita da flor ou queda de pétalas, semelhante aos tratamentos com 0,1 e 1,0 $\mu \mathrm{L} \mathrm{L}^{-1}$ de etileno e controle aberto (Figura 2).

Woltering e Van Doorn (1988) definiram três tipos de respostas das flores ao etileno: aquelas que 
murcham e secam, como ocorre em cravos, orquídeas e petúnias; as flores com queda das pétalas sem sinal visível de murcha como em rosas e gerânio, ou seja, possivelmente o etileno age nesse caso na zona de abscisão das pétalas; e as flores insensíveis ao etileno como íris e lírios. Na rosa 'Osiana' ocorreram sintomas de secamento e murcha das pétalas associada à abscisão de pétalas quando expostas à concentração igual ou superior a $10 \mu \mathrm{L} \mathrm{L}^{-1}$ de etileno por 24 horas (Figura 2). NowAK e RUDNICKI (1990) classificaram as flores quanto ao nível de sensibilidade ao etileno, sendo esta dependente da presença de receptores do etileno; de acordo com esses autores, flores que respondem a concentraçóes de 1 a $3 \mu \mathrm{L} \mathrm{L}^{-1}$ de etileno por 24 horas são classificadas como altamente sensíveis ao etileno, enquanto as flores sensíveis toleram concentrações em geral 10 vezes maiores. A rosa 'Osiana' teve a senescência acelerada quando tratada com $10 \mu \mathrm{L} \mathrm{L}^{-1}$ de etileno por 24 horas, podendo ser classificada como rosa sensível ao etileno. Resultados semelhantes foram observados com a cultivar First Red, cuja longevidade foi reduzida de maneira proporcional à elevação da concentração de etileno entre 1 e $100 \mu \mathrm{L} \mathrm{L}^{-1}$ por 48 horas (ChAmani et al., 2005). Essa variabilidade das cultivares com relação à sensibilidade ao etileno também foi observada em sete genótipos de minirrosas, que tiveram diferentes taxas de abscisão de gemas e folhas, amarelecimento de folhas e senescência das flores (Ahmadi et al., 2009). Em flores na qual a senescência é dependente de etileno, o fito-hormônio se liga a receptores localizados nas membranas, levando respostas em cascata como a síntese de novo da sintase e oxidase do ACC (Reid e Chen, 2007).

Exposiçáo ao etileno nas concentraçóes de 10, 100 e $1000 \mu \mathrm{L} \mathrm{L}^{-1}$ por 24 horas resultaram em acelerada dete- rioração das flores, atingindo nota máxima na escala de senescência (Tabela 2). Nessas concentraçôes de etileno, as flores tiveram acentuada abscisão e secamento das pétalas dentro da 24 horas de aplicação do fito-hormônio. Por outro lado, nas concentraçóes de 0,1 e $1,0 \mu \mathrm{L} \mathrm{L}^{-1}$ de etileno, não houve intensificação da deterioração comparada às flores-controle de dentro e fora da câmara hermética, atingindo notas finais entre -2,6 e -2,9 (Tabela 2). Esses resultados demonstram que para a rosa 'Osiana', há necessidade que o etileno presente na atmosfera de armazenamento atinja uma concentração mínima para iniciar o processo de senescência. As respostas fisiológicas à presença de etileno, em frutos e plantas ornamentais em geral, requerem que os órgãos estejam receptíveis ao fito-hormônio e que haja uma concentração mínima suficiente para haver ligação aos receptores do regulador de crescimento e exercer a ação hormonal (AGAR et al., 1999; Serek et al., 2006).

Tabela 1. Descrição da escala de pontuação adotada para avaliar o desenvolvimento da abertura das flores e senescência da rosa 'Osiana'

\begin{tabular}{|c|c|}
\hline Nota & Descrição \\
\hline 1 & Ponto de colheita comercial \\
\hline 2 & Início de abertura do botão floral \\
\hline 3 & $\begin{array}{l}\text { Flor semiaberta com pétalas externas completamente } \\
\text { expandidas. }\end{array}$ \\
\hline 4 & Flor completamente aberta \\
\hline-1 & $\begin{array}{l}\text { Desenvolvimento inicial de manchas necróticas nas } \\
\text { pétalas externas }\end{array}$ \\
\hline-2 & Presença de manchas necróticas nas pétalas externas \\
\hline-3 & $\begin{array}{l}\text { Presença generalizada de necrose e pétalas com } \\
\text { sintomas de murcha }\end{array}$ \\
\hline-4 & Queda generalizada das pétalas \\
\hline
\end{tabular}
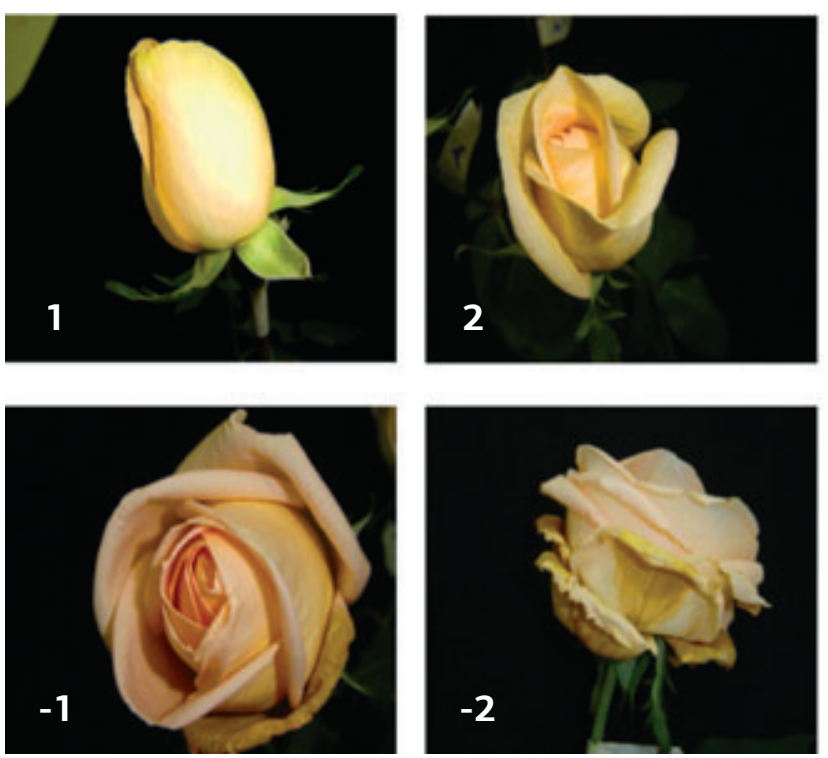
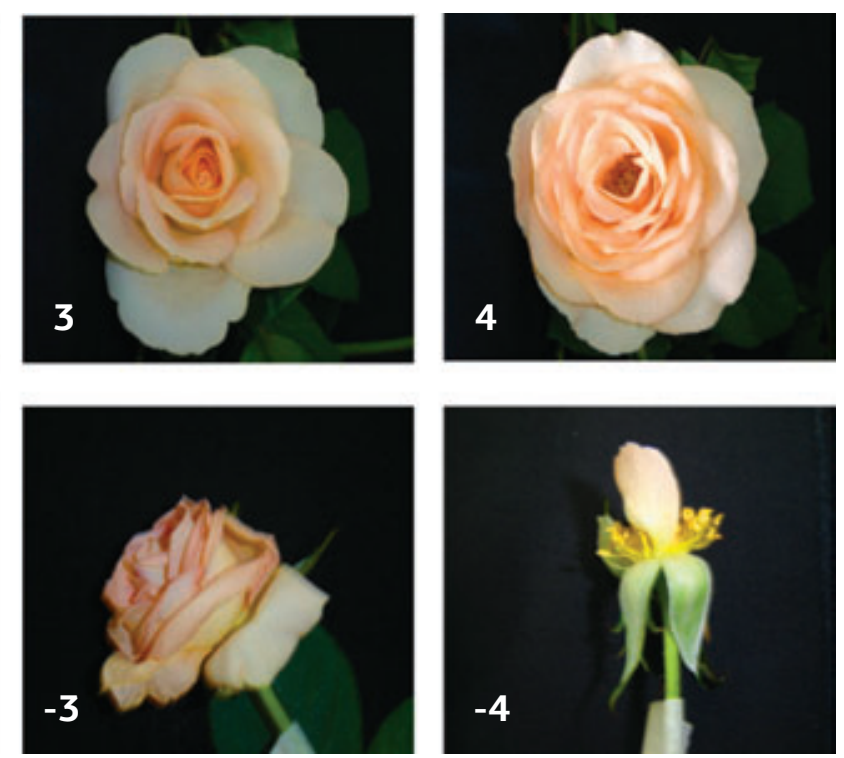

Figura 1. Escala de pontuação adotada do desenvolvimento da abertura das flores $(1,2,3,4)$ e senescência $(-1,-2,-3,-4)$ da rosa 'Osiana'. 


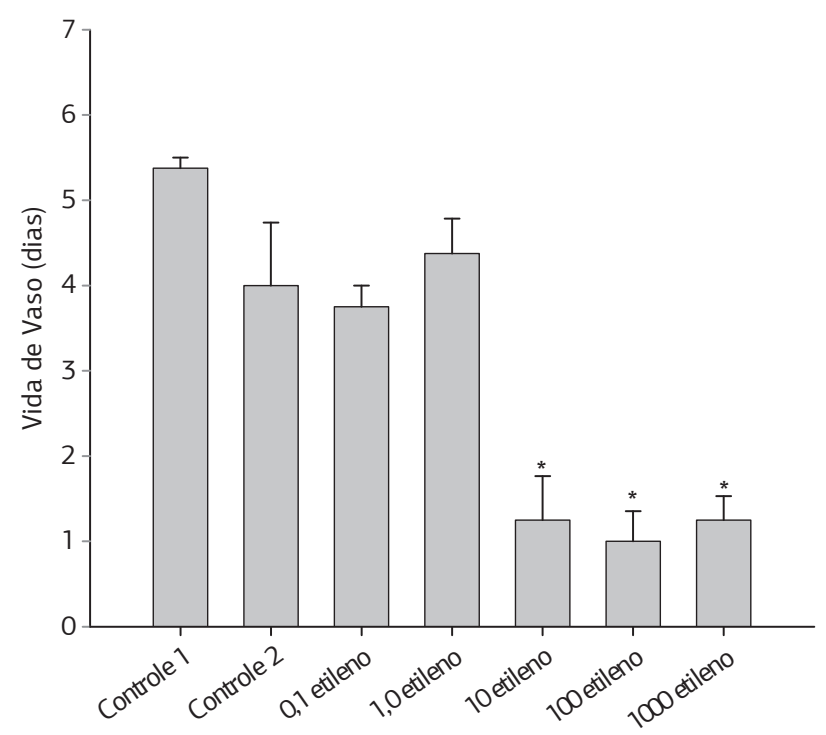

Figura 2. Vida pós-colheita da rosa 'Osiana' controle sistema aberto sem etileno (Controle 1), controle do sistema fechado sem etileno (Controle 2), 0,1; 1,0; 10; 100 e $1000 \mu \mathrm{L} \mathrm{L}^{-1}$ etileno por 24 horas. As barras representam erro-padrão da média. *Efeito significativo sobre longevidade pelo teste Dunnett a $5 \%$ de probabilidade de erro.

Tabela 2. Grau de senescência da rosa 'Osiana' no descarte das flores

\begin{tabular}{ll}
\hline Tratamentos & Notas no descarte \\
\hline Controle 1 (fora da câmara) & $-2,7 \mathrm{bc}$ \\
\hline Controle 2 (dentro da câmara) & $-2,6 \mathrm{c}$ \\
$0,1 \mu \mathrm{L} \mathrm{L}^{-1}$ de etileno & $-2,6 \mathrm{c}$ \\
\hline $1,0 \mu \mathrm{L} \mathrm{L}^{-1}$ de etileno & $-2,9 \mathrm{bc}$ \\
$10 \mu \mathrm{L} \mathrm{L}^{-1}$ de etileno & $-4,0 \mathrm{a}$ \\
$100 \mu \mathrm{L} \mathrm{L}^{-1}$ de etileno & $-4,0 \mathrm{a}$ \\
$1000 \mu \mathrm{L} \mathrm{L}^{-1}$ de etileno & $-4,0 \mathrm{a}$ \\
\hline
\end{tabular}

Letras iguais năo diferem entre si pelo teste de Tukey a $5 \%$ de probabilidade de erro.

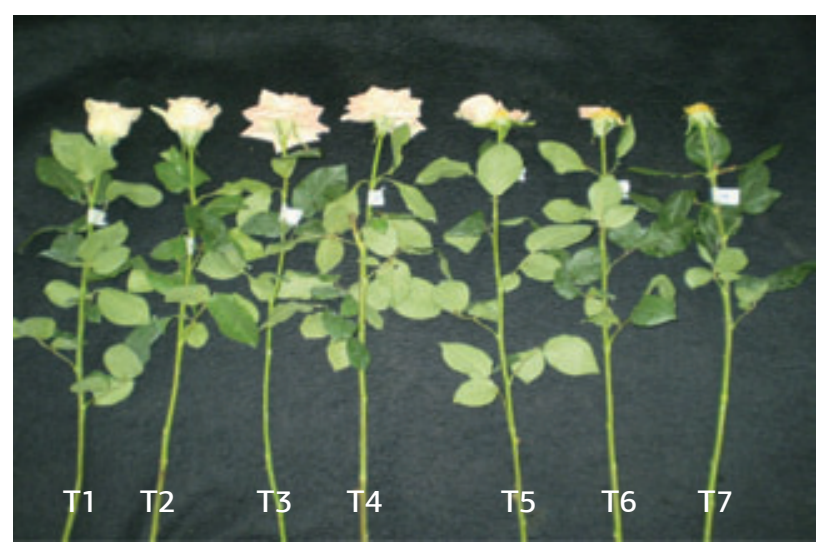

Figura 3. Efeito do etileno sobre a abertura e senescência da flor de rosa 'Osiana' das hastes controle aberto sem etileno (T1), controle do sistema fechado (T2), 0,1 (T3), 1,0 (T4), 10 (T5), 100 (T6) e $1000 \mu \mathrm{L} \mathrm{L}^{-1}$ etileno (T7) por 24 horas.
A presença de 0,1 e 1,0 $\mu \mathrm{L} \mathrm{L}^{-1}$ de etileno na atmosfera pelo período de 24 horas, estimulou a abertura do botáo floral da rosa 'Osiana' (Figura 3). Tal resposta demonstra que há presença de receptores ativos do etileno, responsáveis por respostas que induzem o desenvolvimento da abertura floral (SEREK et al., 2006). No fim do tratamento com o etileno, a flor exposta a 0,1 e $1,0 \mu \mathrm{L} \mathrm{L}^{-1}$ estava no estádio 3 de abertura, enquanto os controles 1 e 2 estavam ainda em estádio de botáo 2 (Figura 3 e Tabela 1). Portanto, as baixas concentrações de etileno foram suficientes para induzir a abertura do botão floral, possivelmente, sem causar aceleração do processo de senescência das pétalas. Segundo Kumar et al. (2008), a rosa pertence ao grupo de flores no qual é sensível ao etileno para estímulo da abertura do botáo floral, mas sem produzir elevadas quantidades do regulador de crescimento durante a senescência. Porém, na análise da sensibilidade de cultivares de rosas ao etileno, verificou-se que o etileno pode ou não influenciar a abertura da flor a qual foi exclusivamente dependente da sensibilidade da cultivar (MACNish et al., 2010). Em cultivares de rosas sensíveis ao etileno, a aplicação dos inibidores da ação do etileno, o íon prata ou 1-metilciclopropeno prolongaram a vida pós-colheita de rosas de corte e vaso, respectivamente (SEREK et al., 1994; Son et al., 2003). Portanto, para a rosa 'Osiana', o uso de inibidores da síntese e da ação do etileno deve ser testado para o controle da abertura do botão floral e da vida pós-colheita. Assim como validar os resultados analisados nesse trabalho.

\section{CONCLUSÃO}

A rosa 'Osiana' pode ser classificada como uma cultivar sensível à ação do etileno. Em concentração igual ou superior a $10 \mu \mathrm{L} \mathrm{L}^{-1}$ de etileno na atmosfera de armazenamento, há redução acentuada da vida pós-colheita da flor, proporcionando o desenvolvimento de necrose, murcha e abscisão precoce das pétalas. A abertura do botão floral é induzida por baixas concentraçóes de etileno $(0,1$ e 1,0 $\mu \mathrm{L}$ $\left.\mathrm{L}^{-1}\right)$, sem afetar a vida pós-colheita das flores.

\section{AGRADECIMENTOS}

Os autores agradecem à Coordenação de Aperfeiçoamento de Pessoal de Nível Superior (CAPES), através da bolsa de estudo concedida a mestranda Delaine Cristina Cordeiro.

\section{REFERÊNCIAS}

AGAR, T.; BIASI, W.V.; MITCHAM, E.J. Exogenous ethylene accelerates ripening responses in Bartlett pears regardless of maturity on growing region. Postharvest Biology and Technology, v.17, p.67-78, 1999. 
AHMADI, N.; MIBUS, H.; SEREK, M. Characterization of ethylene-induced organ abscission in F1 breeding lines of miniature roses (Rosa hybrida L.). Postharvest Biology and Technology, v.52, p.260-266, 2009.

ARORA, A. Biochemistry of flower senescence. In: PALIYAETH, G.; MURR, D.P.; HANDA, A.K.; LURIE, S. (Ed.). Postharvest biology and technology of fruits, vegetables and flowers. Ames: Wiley-Blackwell, 2008. p.51-85.

CHAMANI, E.; KHALIGHI, A.; JOYCE, D.C.; ERVING, D.E.; ZAMANI , Z. A.; MOSTOFI, Y.; KAFI, M. Ethylene and antiethylene treatment effects on cut 'First Red' rose. Journal of Applied Horticulture, v.7, p.3-7, 2005.

FINGER, F.L.; BARBOSA, J.G. Postharvest physiology of cut flowers. In: NOUREDDINE, B.; NORIO, S. (Ed.). Advances in Postharvest Technologies for Horticultural Crops. Kerala: Research Signpost, 2006. p.373-393.

FINGER, F.L.; SANTOS, V.R.; BARBOSA, J.G.; BARROS, R.S. Influência da temperatura na respiração, produção de etileno e longevidade de inflorescências de esporinha. Bragantia, v.65, p.363-368, 2006.

KUMAR, N.; SRIVASTAVA, G.C.; DIXIT, K. Flower bud opening and senescence in roses (Rosa hybrida L.). Plant Growth Regulation, v. 55 , p. $51-81,2008$.

LANDGRAF, P.R.C.; PAIVA, P.D.O. Produção de flores cortadas no estado de Minas Gerais. Ciência e Agrotecnologia, v.33, p.120126, 2009.

LUTTS, S.; KINET, J.M.; BOUHARMONT, J. NaCl-induced senescence in leaves of rice (Oryza sativa L.) cultivars differing in salinity resistance. Annals of Botany, v.78, p.389-398, 1996.

MACNISH, A.J.; LEONARD, R.T.; BORDA, A.M.; NELL, T.A. Genotypic variation in the postharvest performance and ethylene sensitivity of cut rose flowers. HortScience, v.45, p.790-796, 2010.

MATILE, P.; HORTENSTEINER, S.; THOMAS, H.; KRAUTLER, B. Chlorophyll breakdown in senescent leaves. Plant Physiology, v.112, p.1403-1409, 1997.
MULLER, R.; SISLER, E.C.; SEREK, M. Stress induced ethylene production, ethylene binding, and the response to the ethylene action inhibitor 1-MCP in miniature roses. Scientia Horticulturae, v.83, p. $51-59.2000$.

NOWAK, J.; RUDNICK, R.M. Postharvest handling and storage of cut flowers, florist greens, and potted plant. Portland: Timber Press, 1990. 210p.

REID, M.S.; EVANS R.Y; DODGE, L.L. Ethylene and silver thiosulphate influence opening of cut rose flowers. Journal of the American Society for Horticultural Science, v.114, p.436-440, 1989.

REID, M.S.; CHEN, J.-C. Flower senescence. In: GAN, S. (Ed.). Senescence process in plants. Ames: Blackwell Publising, 2007. v.28, p.256-277.

SEREK, M. Ethephon and silver thiosulfate affect postharvest characteristics of Rosa hybrid 'Victory Parade'. HortScience, v.28, p.199-200, 1993.

SEREK, M.; SISLER, E.C.; REID, M.S. Novel gaseous ethylene binding inhibitor prevents ethylene effects in potted flowering plants. Journal of the American Society for Horticultural Science, v.119, p.1230-1233, 1994.

SEREK M.; WOLTERING, E.J.; SISLER, E.C.; FRELLO S.; SRISKANDARAJAH, S. Controlling ethylene responses in flowers at the receptor level. Biotechnology Advances, v.24, p.368-381, 2006.

SON, K.C.; BYOUN, H.J.; YOO, M.H. Effect of pulsing with $\mathrm{AgNO}_{3}$ or STS on the absorption and distribution of silver and the vase life of cut rose 'Red Sandra'. Acta Horticulturae, v.624, p.365-372, 2003.

VAN DOORN, W.G.; WOLTERING, E.J. Physiology and molecular biology of flower senescence. Journal of Experimental Botany, v.59, p.453-480, 2008.

WOLTERING, E.J.; VAN DOORN, W.G. Role of ethylene in senescence of petals - morphological and taxonomical relationships. Journal of Experimental Botany, v.39, p.1605-1616, 1988. 